\title{
Effect of Guidlines for Nurses' Performance Regarding Children Safety in Benha Hospitals
}

\author{
Ebtehal A. Fayed **; Basma R. Abd EL-Sadik *; Amal A. Abdel-Salam* \\ * Assistant Professor of Pediatric Nursing - Faculty of Nursing - Benha University \\ ** B.Sc. in Nursing Science
}

\begin{abstract}
Nurses play a crucial role during provision of care, as they are responsible for maintain children safety in the hospital. Aim of the study: was to assess the effect of guidelines for nurses' performance regarding children safety in Benha hospitals. Design: A quasi-experimental design was utilized in this study. Settings: the study was conducted in pediatric departments at Benha University Hospital and Teaching Hospital. Sample: A convenient sample included 70 nurses (pre and post test). The tools of data collection: Three tools were used in this study. tool (I) a structured interviewing questionnaire to assess nurses knowledge regarding child safety, tool (II) hospital survey on child safety culture to assess nurses attitude, tool (III) an observational checklist followed by designed guidelines booklet. Results: The present study revealed that a statistical significant difference of total knowledge, attitude and practice scores of the studied nurses regarding children safety related age, years of experience and qualification during postintervention. There was positive correlation coefficient between nurses' total knowledge, attitude and practice scores in favor of post intervention. Conclusion: The present study revealed that there was highly statistically significant difference between knowledge, practice and attitude of the studied nurses regarding children safety during pre and post intervention of guidelines regarding children safety. Recommendation: Application guidelines regarding children safety for the nurses working at all pediatric departments to improve their knowledge, attitude and practice.
\end{abstract}

Key words: Children safety; Guidelines; Nurses performance.

\section{Introduction}

Children safety is the prevention of errors and adverse effects to children associated with health care. Children safety is a fundamental principle of health care. Every point in the process of caregiving contains a certain degree of inherent unsafely. Adverse events may result from problems in practice, products, procedures or systems
(American Academy of Pediatrics(AAP), 2011).

Children safety improvements demand a complex system-wide effort, involving a wide range of actions in performance improvement, environmental safety and risk management including infection control, safe use of medicines, equipment safety, safe clinical practice and safe environment of care (Ammouri et al., 2015). 
Children safety culture has been defined as "the values shared among hospital members about what is important, their beliefs about how things operate in the hospital and the interaction of these with work unit and hospital structures and systems, which together produce behavioral norms in the organization that promote safety (Ulrich \& Kear, 2014).

The goal of safety culture is to inform a culture with constant attentiveness and commitment to avoid failures such as giving a wrong dose of medicine or failing to wash hands before seeing children; commitment to resilience, deference to expertise and sensitivity to systems-based practices so hospital must be a "reporting culture." A reporting culture collects, analyzes, and disseminates data about medical errors and adverse events. Front-line staff must be willing and able to report errors and adverse events without fear of retribution. Crucial to this culture are the abilities to communicate easily and confidentially (Christine et al., 2010).

Medical error and children harm have been described and studied for well over a century. However, the medical and nursing professions did not appear to recognize the extent and seriousness of the problem. The great majority of nurses have always been safety conscious in their personal practice but the children safety however is a broader effort that requires thinking beyond the children to consider the characteristics of the whole system of healthcare. The millions of children were being harmed unnecessarily and vast amounts of money being wasted seemed to have escaped everyone's attention. From our current understanding this seems a curious state of affairs (Zegers et al., 2009). knowledge, skills and attitudes necessary to improve the quality and safety of healthcare for children within the work. So integral of safety culture improve safety outcomes and became the drivers for new policies and standards (Sammer\& James, 2011).

\section{Aim of The Study}

This study aimed to evaluate the effect of guidelines for nurses' performance regarding children safety in Benha hospitals through:-

1- Assess nurses' knowledge, practices and attitudes regarding children safety in Benha hospitals.

2- Design and implement guidelines for nurses' knowledge, practices and attitudes regarding children safety in Benha hospitals.

3- Evaluate the effect of guidelines for nurses' knowledge, practices and attitudes regarding children safety in Benha hospitals.

\section{Research Hypothesis}

After applying the guidelines for nurses' performance regarding children safety, nurses' performance will be improved.

\section{Subjects and Method}

\section{Technical Design}

\section{Research design}

A quasi-experimental design was used to carry out the study.

Children safety guideline for nurses enable them in the future to have 


\section{Research settings}

This study was carried out in the pediatric departments at Benha University Hospital and Teaching hospital

\section{Research subjects}

A convenient sample of all available nurses (70) working in pediatric departments (pre and post test) in previous mentioned settings.

\section{Tools of data collection}

Data were collected by using the following tools: -

\section{Tool I: $\quad$ A structured interviewing_questionnaire:}

It was designed by the researcher after reviewing related literatures. It was written in Arabic language and it composed of multiple choice questions and consists of six parts:

Part I- Personal data of nurses such as age, gender, years of experience, work place, level of education and attending of training program about children safety.

Part II- It concerned with nurses' knowledge about children hazards may be take place in the unit such as medication error, it consists of (4) questions about definition, causes, mistakes and management of medication error.

Part III - It concerned with nurses' knowledge regarding fire, it consists of (6) questions about; causes of fire, types of fire extinguisher, characteristics of fire extinguisher, precautions to be taken before starting use fire extinguisher, how to use fire extinguisher and fire prevention.
Part IV- It concerned with nurses' knowledge regarding electricity hazard, it consists of (4) questions about; definition of electricity hazards, causes of accidents resulting from the use of electricity, ways to prevent electricity hazards and ambulance methods in the event of an accident due to electricity.

Part V- It concerned with nurses' knowledge regarding children falling, it consists of (2) questions about; causes of children falling and ways to prevent children falling.

Part VI - It concerned with nurses' knowledge regarding children safety, it consists of (9) questions about definition of children safety, children safety goals in hospital, safe environment, nurse role in improving children safety, rights of the sick child, data that should be available at identification band, when nurse use identification bands, how to prevent bedsores and standard precautions about infection control in hospital. Total questions consist of 25 questions each one scored as the following:

Scoring system of knowledge: The studied nurses answers were compared with the model key answer, where 2 scores was given for complete correct answer, 1 score was given for incomplete correct answer and 0 score for wrong answer and unknown answer. According to the nurses' responses, their total level of knowledge was categorized as the following: Poor level (less than60\%), average level $(60 \%$ to less than $85 \%)$ and good level (85\% to $100 \%)$.

Tool II: Hospital survey on child safety culture:

It was assessed by Norany et al., 2011 and translated into Arabic by the researcher to assess attitude of the studied nurses related to children safety. It measures the different aspect of children 
safety culture among nurses uses selfadministrated questionnaire.

\section{Scoring system for the attitude}

A score was calculated according to Likert scale. Their total level of attitude was categorized as the following: disagree attitude (less than 20\%), uncertain attitude (20\% to less than $40 \%)$ and agree attitude (40\% to less than $60 \%$ )

\section{list:}

\section{Tool III: An observational check}

It was evaluated nurses practice and adapted from Hales et al., (2011) and used to assess nurses practice related to children safety (vital signs procedure, pediatric cardiopulmonary resuscitation procedure, oxygen therapy procedure, nebulizer care procedure, administration medication, infection control measures ).

\section{Scoring system for each}

The studied nurses answers were compared with the observational checklist sheet where 2 scores was given for each step done competent, 1 score was given for each step done incompetent and 0 score for each step not done. According to the nurses' responses, their total level of practice was categorized as the following: done competent (98 - 100\%), done incompetent (50\% to less than98\%) and not done (less than 50\%).

\section{Designed guidelines booklet}

Designed guidelines booklet prepared by the researcher and contain the following: introduction, definition of children safety, children safety goals in hospital, relationship between children safety and children safety culture, nurse role in improving children safety, rights of the sick child, data that should be available at identification band, when nurse use identification bands, how to prevent bedsores, standard precautions in infection control in hospital, some errors may be take place in the unit such as medication error, children falling, electricity hazard and firing. A booklet was devolved and supplemented by photos and illustrations to help the nurses understanding of the content.

\section{of tools}

Content validity and reliability

The data collected tools were revised by a panel of three experts in field of pediatric nursing to test face and content validity. Modifications of the study tools were done according to the panel judgment on clarity of sentences, appropriateness of content and sequence of items.

Internal reliability of all items of the tools was assessed using Cronbach's co-efficiency alpha. It was (0.79) for structured interviewing questionnaire and knowledge of the studied nurses regarding children safety, $(0.83)$ for tool 2 to assess attitude of the studied nurses related to children safety and (0.86) for tool 3 assess performance of the studied nurses related to children safety.

\section{Ethical considerations}

The researcher explained the aim of the study to the nurses. They were informed that the study is harmless. The researcher secured that all the gathered data are confidential and are used for the research purpose only. The nurses were informed that they are optionally allowed either participate or not in the study and they have the right to withdraw at any time. An oral consent was taken from the nurses. 


\section{Technical Design}

\section{Pilot study}

A pilot study was carried out on $10 \%(\mathrm{n}=7)$ of the expected sample size to test the content validity and applicability of study tools and to estimate the time needed to fill the questionnaire. Some questions and items were omitted, added or rephrased and then the final forms were developed experts reviewed the tools for clarity, relevance, comprehensive and simplicity. Participants involved in the pilot study were included from the study sample. This phase take one month.

\section{Field of work}

The actual field work was carried out over a period of 6 months starting from beginning of November 2016 to the end of April 2017, along four days per week and six hour per day which divided two days (Saturday and Sunday ) in Teaching Hospital and another two days (Monday and Tuesday ) in Benha University Hospital. Data were collected throughout two phases of the assessment for nurses. At first, the researcher assessed nurses' knowledge and attitudeS about children safety, the tools were filled individually by the nurses then the researcher observed nurses practice during their actual nursing care. The tools were filled by the researcher; the assessment was done before implementing of designed guidelines. The second phase of assessment was done after implementation of designed guidelines to evaluate the impact of designed guidelines.

\section{Practical part: Nurse's} knowledge, attitude and practics were assessed through using the interviewing questionnaire, observational checklist and modified likert scale, as pre- test. Then the designed guidelines booklet was distributed to all nurses and explained to nurses in form of sessions as the following:

Session one: introduction, definition of children safety, children safety goals in hospital, relationship between children safety and children safety culture, nurse role in improving children safety. Session two: Rights of the sick child, data that should be available at identification band, when nurse use identification bands, how to prevent bedsores, standard precautions in infection control in hospital. Session three: some errors some error may be take place in the unit such as medication error, children falling, electricity hazard and firing. A booklet was devolved and supplemented by photos and illustrations to help the nurses understanding of the content. After implementation the post test was carried out to assess nurse's knowledge, attitudes and practices using the same forms of the pretest this helped to evaluate the effect of the implemented guidelines. An immediate follow up for evaluation of nurse's knowledge, attitudes and practices was conducted immediately after the intervention.

\section{Administrative design}

An official permission was obtained from the dean of Benha faculty of nursing and directed to hospitals' administrators of the previously mentioned settings with full explanation of the study purpose and methods of data collection.

\section{Statistical design}

The collected data were organized, tabulated and analyzed using electronic computer and Statistical Package for Social Sciences (SPSS) version 20. Descriptive statistics were calculated for 
the data in the form of: Mean, standard deviation, frequency and percentage. Distribution of qualitative data in analytical statistics, inter-group comparison of categorical data was performed by using chi-square test $(P$ value), Fisher Exact Test. Also person correlation coefficient test was used $P$ value $\leq 0.05$ was consider statistical significant difference and $P$ value $\leq 0.001$ was considered highly significant difference in all analyses.

\section{Results}

Table (1): shows that, the mean age of the studied nurses were $33.67 \pm$ 8.04 years while $45.8 \%, 31.4 \%$ and $21.4 \%$ of the studied nurses were diploma of technical institute, diploma of nursing and bachelor degree respectively. Regarding to years of experience, the mean of experience $(8.51 \pm 3.86)$ while less than one quarter of the studied nurses work in pediatric ward and all studied nurses $100 \%$ are female and not attend any training programs related to children safety

Table (2): shows that, there was a highly statistical significant difference ( $P$ $\leq 0.001$ ) in total knowledge of the studied nurses related to children hazards in hospital in favor of post intervention.

Figure (1): shows that, less than two thirds $(57.1 \%)$ of the studied nurses have average knowledge related to children safety in pre intervention. While $80 \%$ of them have good knowledge related to children safety in post intervention..

Figure (2): shows that, more than two third $(68.6 \%)$ of the studied nurses had uncertain attitude toward children safety in pre intervention, while more than three quarter $(78.6 \%)$ of them have uncertain attitude toward children safety in post intervention.

Figure (3): shows that, more than two thirds $(68.5 \%)$ of the studied nurses have average practice related to children safety in pre intervention. While $(58.6 \%)$ of them have competent practice related to children safety in post intervention.

Table (3): shows that, a statistical significant difference $(\mathrm{P} \leq 0.05)$ between total knowledge score of the studied nurses regarding children safety related age, years of experience and qualification while there was a no statistical significant difference between total knowledge score of the studied nurses regarding children safety related working units

Table (4): shows that, there is positive correlation coefficient between nurse's total between total knowledge, attitude and practice scores $(\mathrm{P} \leq 0.001)$ in favor of post intervention. 
Table (1): Distribution of the study nurses according to personal characteristics $(\mathbf{n}=\mathbf{7 0})$

\begin{tabular}{|c|c|c|}
\hline Items & No. & $\%$ \\
\hline \multicolumn{3}{|l|}{ Age (years) } \\
\hline$<20$ & 2 & 2.9 \\
\hline $20<30$ & 25 & 35.7 \\
\hline $30<40$ & 28 & 40.0 \\
\hline$\geq 40$ & 15 & 21.4 \\
\hline Range & \multicolumn{2}{|c|}{$19-54$} \\
\hline Mean \pm SD & \multicolumn{2}{|c|}{$33.67 \pm 8.04$} \\
\hline \multicolumn{3}{|l|}{ Qualification } \\
\hline -Diploma of nursing & 22 & 31.4 \\
\hline -Diploma of technical institute & 32 & 45.8 \\
\hline -Bachelor degree in nursing & 15 & 21.4 \\
\hline -Master degree in nursing & 1 & 1.4 \\
\hline \multicolumn{3}{|l|}{ Years of experience } \\
\hline $1<5$ & 19 & 27.1 \\
\hline $5<10$ & 30 & 42.9 \\
\hline$\geq 10$ & 21 & 30.0 \\
\hline Range & \multicolumn{2}{|c|}{$1-20$} \\
\hline Mean \pm SD & \multicolumn{2}{|c|}{$8.51 \pm 3.86$} \\
\hline \multicolumn{3}{|l|}{ Working units } \\
\hline -Pediatric ward & 24 & 34.3 \\
\hline -Pediatric ICU & 6 & 8.6 \\
\hline -NICU & 22 & 31.4 \\
\hline -Pediatric dialysis & 11 & 15.7 \\
\hline -Pediatric outpatient & 7 & 10.0 \\
\hline \multicolumn{3}{|c|}{$\begin{array}{l}\text { Attendance of training programs related to } \\
\text { children safety }\end{array}$} \\
\hline No & 70 & 100.0 \\
\hline
\end{tabular}


Table (2): Distribution of total knowledge of studied nurses' regarding to children hazards in hospital.

\begin{tabular}{|c|c|c|c|c|c|c|c|c|c|c|c|c|c|c|}
\hline \multirow{3}{*}{$\begin{array}{l}\text { Knowledge } \\
\text { About }\end{array}$} & \multicolumn{6}{|c|}{ Pre-intervention } & \multicolumn{6}{|c|}{ Post intervention } & \multirow{3}{*}{$x^{2}$} & \multirow{3}{*}{$\begin{array}{c}\text { p- } \\
\text { value }\end{array}$} \\
\hline & \multicolumn{2}{|c|}{ Good } & \multicolumn{2}{|c|}{ Average } & \multicolumn{2}{|c|}{ Poor } & \multicolumn{2}{|c|}{ Good } & \multicolumn{2}{|c|}{ Average } & \multicolumn{2}{|c|}{ Poor } & & \\
\hline & No. & $\%$ & No. & $\%$ & No. & $\%$ & No. & $\%$ & No. & $\%$ & No. & $\%$ & & \\
\hline $\begin{array}{l}\text { Medication } \\
\text { error in } \\
\text { hospital }\end{array}$ & 7 & 10.0 & 45 & 64.3 & 18 & 25.7 & 58 & 82.9 & 11 & 15.7 & 1 & 1.4 & 75.869 & $0.000 * *$ \\
\hline $\begin{array}{l}\text { - Firing } \\
\text { hazards in } \\
\text { hospital }\end{array}$ & 3 & 4.3 & 35 & 50.0 & 32 & 45.7 & 49 & 70.0 & 21 & 30.0 & 0 & 0.0 & 76.192 & $0.000 * *$ \\
\hline $\begin{array}{l}\text { - Electricity } \\
\text { hazards in } \\
\text { hospital }\end{array}$ & 5 & 7.1 & 23 & 32.9 & 42 & 60.0 & 51 & 72.9 & 19 & 27.1 & 0 & 0.0 & 80.167 & $0.000 * *$ \\
\hline $\begin{array}{l}\text { - Children } \\
\text { falling in } \\
\text { hospital }\end{array}$ & 16 & 22.9 & 33 & 47.1 & 21 & 30.0 & 55 & 78.6 & 14 & 20.0 & 1 & 1.4 & 47.285 & $0.000 * *$ \\
\hline $\begin{array}{l}\text { - Child } \\
\text { safety in } \\
\text { hospital }\end{array}$ & 9 & 12.9 & 47 & 67.1 & 14 & 20.0 & 53 & 75.7 & 17 & 24.3 & 0 & 0.0 & 59.288 & $0.000 * *$ \\
\hline Total & 4 & 5.7 & 40 & 57.1 & 26 & 37.2 & 56 & 80.0 & 14 & 20.0 & 0 & 0.0 & 83.585 & $0.000^{* * *}$ \\
\hline
\end{tabular}

**A highly statistical significant difference $(\mathrm{P} \leq \mathbf{0 . 0 0 1})$

Figure (1): Distribution of the studied nurses' total knowledge toward children safety

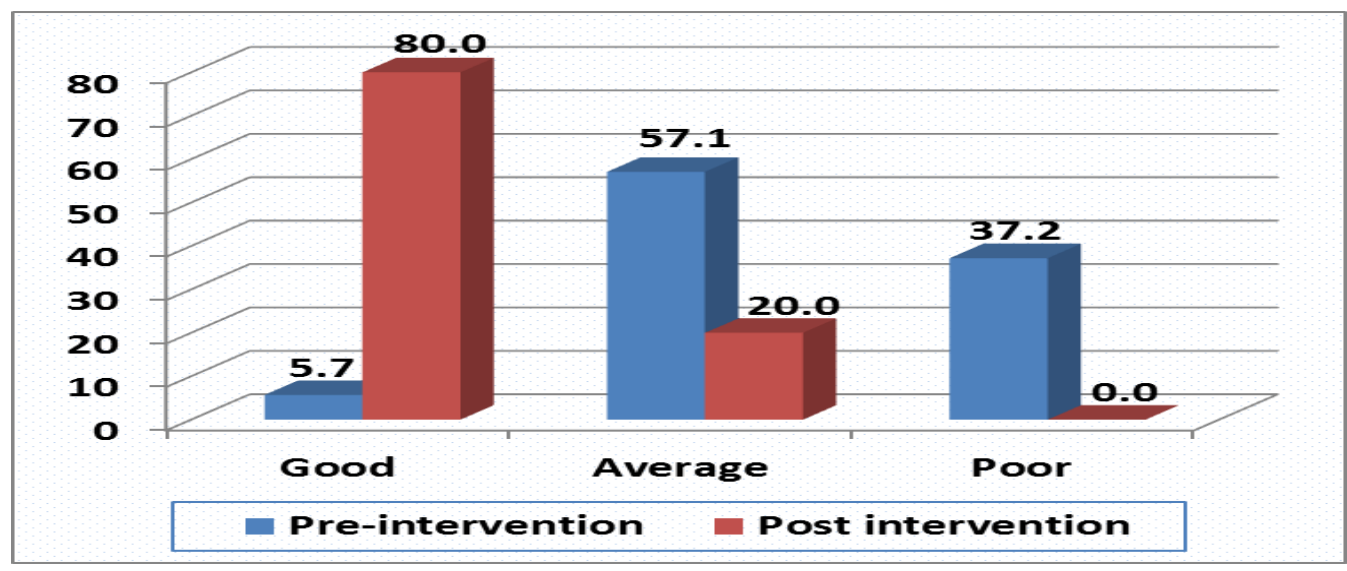


Fig. (2): Distribution of the studied nurses' total attitudes toward children safety

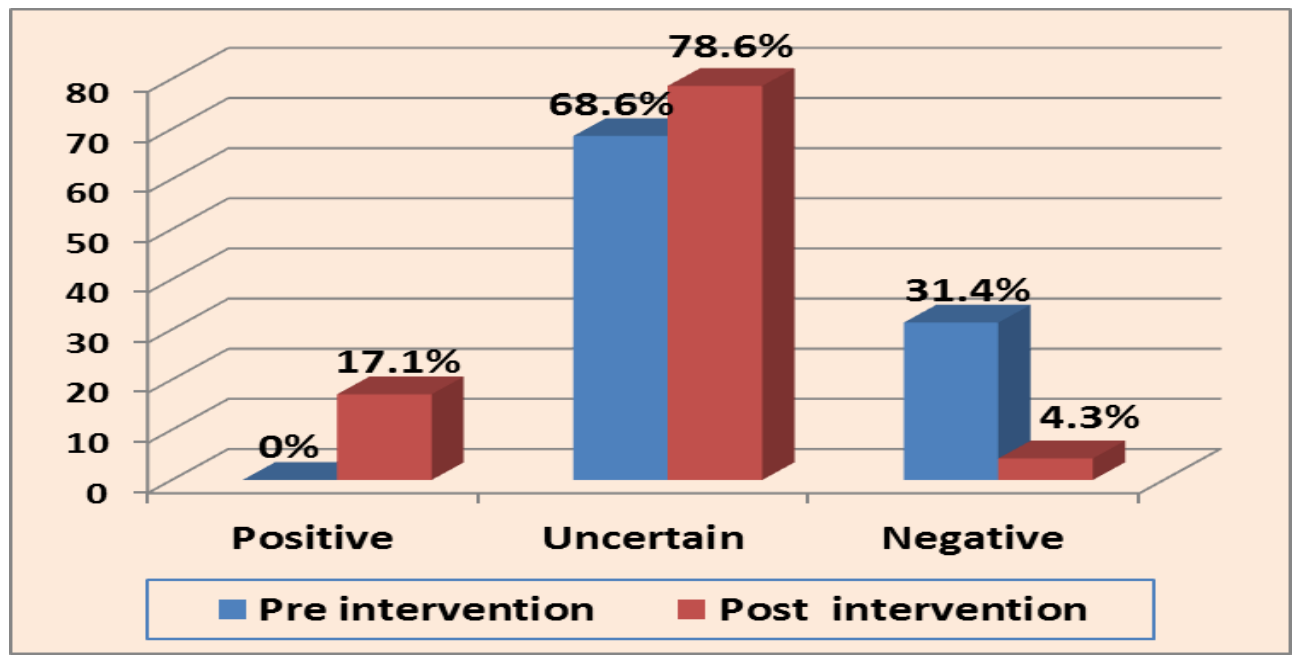
in hospital

Figure (3): Distribution of the studied nurses' practices toward children safety

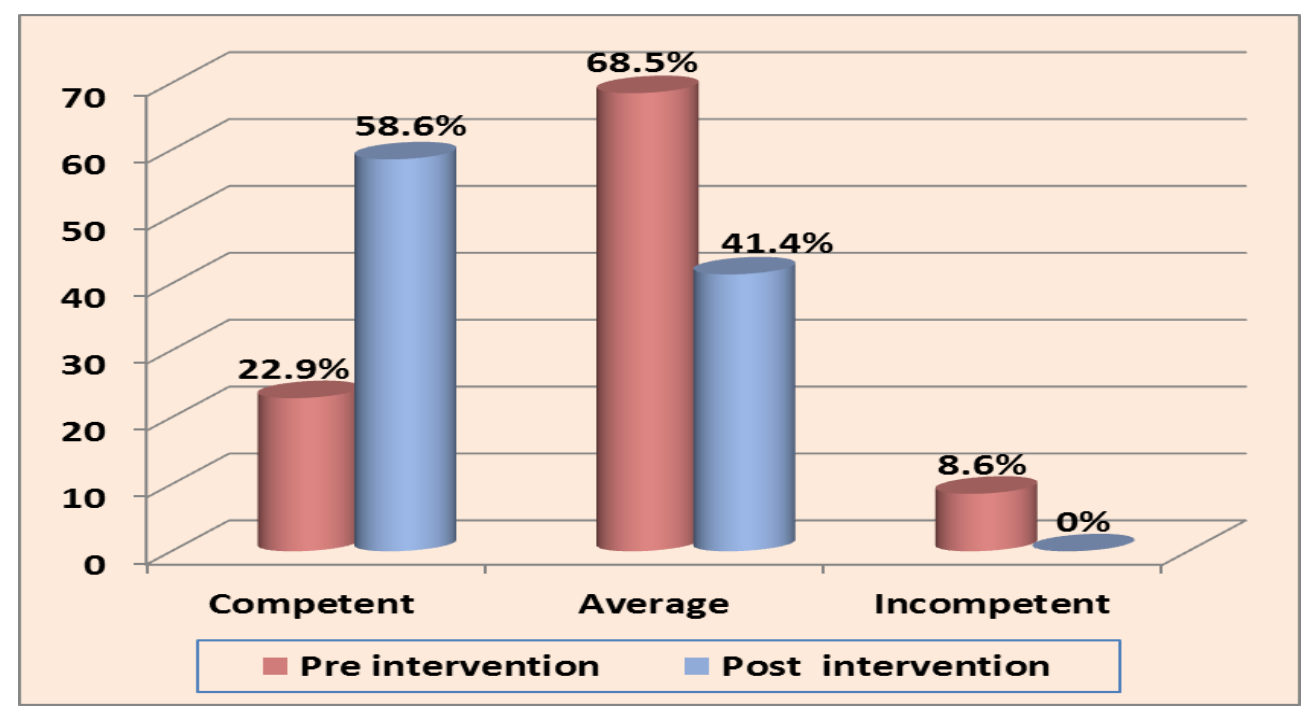


Ebtehal A., Basma R., Amal A.

Table (3): Relation between level of nurse's knowledge pre, post intervention and socio-demographic characteristics

\begin{tabular}{|c|c|c|c|c|c|c|c|c|c|c|}
\hline \multirow{3}{*}{$\begin{array}{l}\begin{array}{r}\text { Level of } \\
\text { knowledge }\end{array} \\
\text { Variable }\end{array}$} & \multicolumn{6}{|c|}{ Pre intervention } & \multicolumn{4}{|c|}{ Post intervention } \\
\hline & \multicolumn{2}{|c|}{ Good } & \multicolumn{2}{|c|}{ Average } & \multicolumn{2}{|c|}{ Poor } & \multicolumn{2}{|c|}{ Good } & \multicolumn{2}{|c|}{ Average } \\
\hline & No & $\%$ & No & No & $\%$ & No & No & $\%$ & No & $\%$ \\
\hline \multicolumn{11}{|l|}{ Age (years) } \\
\hline$<20$ & 1 & 25.0 & 1 & 2.5 & 0 & 0.0 & 19 & 33.9 & 2 & 14.3 \\
\hline $20<30$ & 2 & 50.0 & 15 & 37.5 & 8 & 30.8 & 23 & 41.1 & 6 & 42.9 \\
\hline $30<40$ & 1 & 25.0 & 20 & 50.0 & 7 & 26.9 & 14 & 25.0 & 5 & 35.7 \\
\hline$\geq 40$ & 0 & 0.0 & 4 & 10.0 & 11 & 42.3 & 0 & 0.0 & 1 & 7.1 \\
\hline p- value & \multicolumn{6}{|c|}{$0.004 * *$} & \multicolumn{4}{|c|}{$0.019 *$} \\
\hline \multicolumn{11}{|l|}{ Qualification } \\
\hline $\begin{array}{l}\text {-Diploma of } \\
\text { nursing }\end{array}$ & 2 & 50.0 & 12 & 30.0 & 8 & 30.8 & 21 & 37.5 & 1 & 7.1 \\
\hline $\begin{array}{l}\text {-Diploma of } \\
\text { technical } \\
\text { institute }\end{array}$ & 1 & 25.0 & 17 & 42.5 & 14 & 53.8 & 26 & 46.4 & 6 & 42.9 \\
\hline $\begin{array}{l}\text {-Bachelor } \\
\text { degree in } \\
\text { nursing }\end{array}$ & 0 & 0.0 & 11 & 27.5 & 4 & 15.4 & 8 & 14.3 & 7 & 50.0 \\
\hline $\begin{array}{l}\text {-Master degree } \\
\text { in nursing }\end{array}$ & 1 & 25.0 & 0 & 0.0 & 0 & 0.0 & 1 & 1.8 & 0 & 0.0 \\
\hline p- value & \multicolumn{6}{|c|}{$0.003^{* *}$} & \multicolumn{4}{|c|}{$0.017 *$} \\
\hline \multicolumn{11}{|l|}{$\begin{array}{l}\text { Years of } \\
\text { experience }\end{array}$} \\
\hline $1<5$ & 4 & 100.0 & 7 & 17.5 & 8 & 30.8 & 19 & 33.9 & 0 & 0.0 \\
\hline $5<10$ & 0 & 0.0 & 25 & 62.5 & 5 & 19.2 & 24 & 42.9 & 6 & 42.9 \\
\hline$\geq 10$ & 0 & 0.0 & 8 & 20.0 & 13 & 50.0 & 13 & 23.2 & 8 & 57.1 \\
\hline p- value & \multicolumn{6}{|c|}{$0.000^{* *}$} & \multicolumn{4}{|c|}{$0.011^{*}$} \\
\hline \multicolumn{11}{|l|}{ Working units } \\
\hline -pediatric ward & 0 & 0.0 & 15 & 37.5 & 9 & 34.7 & 19 & 33.9 & 5 & 35.7 \\
\hline -pediatric ICU & 0 & 0.0 & 5 & 12.5 & 1 & 3.8 & 4 & 7.1 & 2 & 14.3 \\
\hline -NICU & 2 & 50.0 & 12 & 30.0 & 8 & 30.8 & 19 & 33.9 & 3 & 21.4 \\
\hline $\begin{array}{l}\text {-pediatric } \\
\text { dialysis }\end{array}$ & 1 & 25.0 & 5 & 12.5 & 5 & 19.2 & 9 & 16.2 & 2 & 14.3 \\
\hline $\begin{array}{l}\text {-pediatric } \\
\text { outpatient }\end{array}$ & 1 & 25.0 & 3 & 7.5 & 3 & 11.5 & 5 & 8.9 & 2 & 14.3 \\
\hline p- value & \multicolumn{6}{|c|}{0.692} & \multicolumn{4}{|c|}{0.813} \\
\hline
\end{tabular}

*A statistical significant difference $(\mathrm{P} \leq 0.05) \quad$ **A highly statistical significant difference $(\mathrm{P} \leq 0.001)$ 
Table (4): Correlation coefficient between nurse's total knowledge, attitude and practice scores pre and post intervention

\begin{tabular}{|c|c|c|c|c|}
\hline \multirow{3}{*}{ Variable } & \multicolumn{4}{|c|}{ Total knowledge score } \\
\hline & \multicolumn{2}{|c|}{$\begin{array}{c}\text { Pre-intervention } \\
\mathbf{n}=\mathbf{7 0}\end{array}$} & \multicolumn{2}{|c|}{$\begin{array}{c}\text { Post intervention } \\
n=70\end{array}$} \\
\hline & $\mathbf{r}$ & $\mathbf{P}$ & $\mathbf{R}$ & $\mathbf{P}$ \\
\hline Total attitudes score & 0.573 & $0.000 * *$ & 0.649 & $0.000 * *$ \\
\hline Total practice sscore & 0.590 & $0.000 * *$ & 0.622 & $0.000 * *$ \\
\hline
\end{tabular}

\section{Discussion}

Findings of this study (table 1) showed that, mean age of the studied children was $9.25 \pm 1.85$ years and Regarding personal data of the studied nurses, the results of the present study revealed that, less than half of the studied nurses were ranged from 25-30 years with mean age of $33.67 \pm 8.04$ year and all of the study nurses were female. This result was similar to the results of a study by Ahmed, (2013) in a study entitled "Patient safety culture among physicians in Benha University Hospital". In this study the mean age of the studied sample was $28.25 \pm 5.504$ and differ in sex of sample which wasm more half of them were females.

In relation to years of experience of the studied nurses, the finding of the current study showed that less than half of the studied nurses had experience between $5>10$ years in nursing field. This is similar to results of the study done by El-Salieh, (2012), entitled of "nurses' perception and developing an improvement plan regarding children safety in Benha hospitals". Who found that less than half of staff nurses had experience between 5>10 years in nursing field.

In relation to attendance training programs related to children safety, the finding of the current study (table 1) showed that all of the studied nurses not attending training programs related to children safety. This is similar to results of the study done by El-Salieh, (2012), who showed that $78 \%$ of staff nurses didn't attending training programs related to children safety. This may be due to improper provision of conduction and lack of supervisor awareness about the importance of safety. The training programs play important role in enhancing child safety and updating the nurse's knowledge, practice and improving safety of care given to the child. The researcher believes that attending training program by nurses especially in pediatrics unit is crucial to provide children safety during nursing care.

Regarding the studied nurses' knowledge (table 3) about children hazards (Medication error, firing hazards, electricity hazards, children falling and child safety) in hospital has poor score. This could be attributed to the fact that all of nurses didn't receive any training program about children safety as well as they didn't develop their selves with updated knowledge. While in post intervention, it was noted that nurse's knowledge about children hazards had good score. This could be attributed to the aim of the study.

The current study (fig. 1)showed that, more than two thirds of studied nurses have average knowledge regarding to children safety in hospital in pre intervention These findings were supported by the results of the study done 
by El-Salieh, (2012), who recommended that, developing and updating universal protocols and guidelines about safety aspect. In this study the researcher apply guidelines about children safety in hospital. The current study shows that, there was a highly statistical significant difference in favor of post intervention.

The current study (fig. 2)showed that,more than two third of the studied nurses had uncertain attitude regarding children safety in pre intervention while more than three quarters of the studied nurses had uncertain attitude regarding children regarding children safety in post intervention. Moreover, there was a statistical significant difference and $(\mathrm{P} \leq$ 0.05) a highly statistical significant difference $(\mathrm{P} \leq 0.001)$ in favor of post intervention. These findings were supported by the results of the study done by Cervasio et al., (2013), entitled "Attitudes of nurses toward children with disabilities: the attitudes of nursing students toward children with disabilities". Who showed that, there positive change in the attitudes of nurses toward children with disabilities who receive disability education course as compared to nurses who did not receive the disability education course pretest, immediate posttest and after one month.

The present study (fig.3) showed that, more than two third of the studied nurses have incompetent practice related to children safety in pre intervention, while more than half of them have competent practice related to children safety in post intervention. These findings were supported by the results of the study done by Suominen. T., (2016) entitled "health care professionals' knowledge and attitudes regarding patient safety and skills for safe patient care" who found that they have positive safety attitudes to contextual issues and procedures, to event reporting and an improvement was found in safety practice after health care professionals had received training.

The current study (table 4)found that there was a statistical significant difference total knowledge score of the studied nurses regarding children safety related age, years of experience and qualification while there was a no statistical significant difference between total knowledge score of the studied nurses regarding children safety related working units. This supported by study by Fayed et al., (2016) entitled "effect of instructional program on nurse's compliance with universal precautions of infection control", who declared that continuing education regardless of age can significantly get better infection control practices and decrease rate of infection. Also there are a highly statistical significant difference between nurse's knowledge, practices and their socio demographic data (level of education and previous training).

Correlation coefficient between total knowledge, attitudes and practice scores, the present study (table 5)revealed that there is positive correlation coefficient between nurse's total between total knowledge, attitudes and practices scores in favor of post intervention. Which means that knowledge of nurses using adequate information and demonstration will be achieve improvement in nurse's practice. These findings is supported by Rosenthal et al., (2012) entitled "device-associated nosocomial infection rates in intensive care units of Argentina. Infection hospital epidemiology" who found that the educational program about the infection control precautions are significantly influenced the participant's performance. 


\section{Conclusion:}

Based on the results of the present study it was concluded that there was highly statistically significant difference between knowledge, practices and attitudes of the studied nurses regarding children safety during pre and post intervention guidelines regarding children safety. This conclusion leads to the acceptance of the study hypothesis that after applying guidelines for nurses' performance regarding children safety, nurses' performance will be improved in Benha hospitals

\section{Recommendations:}

Based on the findings of the present study, the following recommendations suggest

- Designing children safety guidelines as each hospital policy to provide safe work environment for nurses and children to reduce the occurrence of errors.

- Improve errors reporting system and policy among nurses by removing barriers, clarifying the importance of reporting and encouraging them to report errors with supporting from nursing administration.

- Coordination between all health care team members especially physicians, pharmacists and improve their role to reduce medical errors and promote children safety.

- Application children safety guidelines in all hospitals regarding maintain children safety in hospital.

\section{References}

Ahmed, G., (2013): Concept and attitude toward sick child's rights at pediatric surgical units, Master Thesis, Faculty of Nursing, Benha University.

American Academy of Pediatrics (AAP), (2011): Hospital Care Steering Committee on Quality improvement and Management and Committee on Principles of Pediatric Patient Safety: Reducing Harm Due to Medical Care. The Official Journal of the American Academy of Pediatrics, 127(6):119 127.

Ammouri, A.; $\quad$ Muliira, J.; Geethakrishnan, R. \& Al Kindi, S. (2015): Patient Safety Culture among Nurses. International Nursing Review; 62(1): 102-110.

Christine, E.; Sammer, R., Kristine, L.; Karan, P.; Douglas, A. \& Nuha, A. (2010): What is Patient Safety Culture? A Review of the Literature Journal of Nursing Scholarship 2(42): 156-165.

El-Salieh, A. (2012): Nurses' Perception and Developing an Improvement Plan Regarding Children Safety in Benha Hospitals at Benha City, Master Degree, Faculty of Medicine, Benha University, Egypt P:102.

Fayed, M.; Hanan, T.; Elbahnasawy, T. ; \& Omar, K. (2016): Effect of Instructional Program on Nurses Compliance with Universal Precautions of Infection Control. International Journal of Novel Research in Health care and Nursing; 3(1): 81-92.

Hales, B.; Terblanche, M.; Fowler, R. \& Sibbald, W. (2013): Development of medical checklists for improved quality of patient care. Available at: http://www.hpoe.org/checklistsimprove-patient-safety. 
Norany D.; Baghaie, R.; Khalkhaly, H., \& Pirnegad, H.,(2011): Evaluating Patient Safety Culture in Personnel of Academic Hospitals in Urmia University of Medical Sciences. Iran J Nurs Midwifery Urima Univ Med Sci, 20(4):490 -495.

Sammer, C \& James, B.(2011): Patient Safety Culture, The Nurses Unit Leader's Role, The Online Journal of Issues in Nursing. 16 (3):33-36.

Suominen. T., (2016): Health Care Professionals' Knowledge and Attitudes Regarding Patient Safety and Skills for Safe Patient Care. Master Thesis University of Tampere. P: 112 .
Ulrich, B. \& Kear, T. (2014): Patient Safety and Patient Safety Culture: Foundations of Ex - Cellent Health Care Delivery. Nephrology Nursing Journal, 41(5) :447-456, 505.

Zegers, M.; de Bruijne, M.; Wagner, C.; Hoonhout, L.; Waaijman, R. \& Smits, M. (2009): Adverse Events and Potentially Preventable Deaths in Dutch Hospitals: Results of A Retrospective Patient Record Review Study. Quality and Safety in Health Care, 18 (4) 297-302.

Cervasi, V.; Guzman, S.; \& Crinch, C., (2013), entitled "Attitudes of nurses toward children with disabilities: the attitudes of nursing students toward children with disabilities", 25(3):p251-5. 